\title{
A new Co(II) coordination solid with mixed oxygen, carboxylate, pyridine and thiolate donors exhibiting canted antiferromagnetism with $T_{\mathrm{C}} \approx 68 \mathrm{~K}$
}

\author{
Simon M. Humphrey, $\dagger^{a}$ Antonio Alberola, ${ }^{a}$ Carlos J. Gómez García ${ }^{b}$ and Paul T. Wood*a \\ Received (in Cambridge, UK) 13th January 2006, Accepted 23rd February 2006 \\ First published as an Advance Article on the web 8th March 2006 \\ DOI: $10.1039 / \mathrm{b} 600347 \mathrm{~h}$
}

Reaction of Co(II) chloride with the sodium salt of 2-mercaptonicotinic acid in water at $200{ }^{\circ} \mathrm{C}$ results in the formation of $\mathrm{Co}_{4}(2-\mathrm{mna})_{4}\left(\mathrm{H}_{2} \mathrm{O}\right)$, which orders as a canted antiferromagnet at $68 \mathrm{~K}$.

The synthesis of new metal-organic coordination polymers continues to attract a great deal of interest since such materials have been shown to exhibit highly desirable solid-state properties such as magnetism, ${ }^{1}$ nanoporosity, ${ }^{1,2}$ second-harmonic generation ${ }^{3}$ and show promise for use in molecular electronics. ${ }^{4}$ They may also be doped with other metals to produce active heterogeneous catalysts. ${ }^{5}$ In particular, materials that have thermally-accessible magnetically bistable states have the potential to be utilized in data storage on the molecular level. ${ }^{6}$ One of the major obstacles impeding progress in this area is the very low temperatures at which magnetic ordering occurs. ${ }^{67}$ Extensive study of Prussian blue derivatives has produced materials which order above room temperature. ${ }^{8}$ Good metal-ligand orbital overlap is expected to increase the strength of magnetic exchange due to a greater degree of spin delocalisation onto the bridging ligand. ${ }^{9}$ Thiolate ligands are attractive candidates for such an approach, but success has previously been limited due to the ease of disulfide formation for such ligands. We have recently shown that hydrothermal synthesis is an effective way of preparing thiolate networks whilst minimising the possibility of disulfide formation, ${ }^{10}$ presumably due to the inherently reducing nature of high temperature water. The thiolate-mediated magnetic exchange in these materials is still relatively weak, presumably as a result of unfavorable $\mathrm{M}-\mathrm{S}-\mathrm{M}$ bridging angles. However, we now report strong superexchange and weak ferromagnetism due to spin canting in a highly complex and dense coordination solid containing 5- and 6-coordinate $\mathrm{Co}^{\mathrm{II}}$, $\left[\mathrm{Co}_{4}\left(2-\mathrm{mna}_{4}\left(\mathrm{OH}_{2}\right)\right]\right.$ (1) (2-mna = 2-mercaptonicotinate, $\left.\left(\mathrm{NC}_{5} \mathrm{H}_{3}(\mathrm{~S})\left(\mathrm{CO}_{2}\right)-2,3\right)^{2-}\right)$ (Fig. 1). Spherical clusters of very fine branched (fern leaf-like) deep red needles were initially observed from the hydrothermal reaction of $\mathrm{CoCl}_{2}$ with 2- $\mathrm{mnaH}_{2}$ and $\mathrm{KOH}$ (ratio $1: 1: 2$ ), although much better samples were prepared when $\mathrm{NaOH}$ was employed as the base.t Single crystal X-ray diffraction $\S$ led to the identification of the low symmetry 3 -dimensional polymer $\mathbf{1}$ (in the non-centrosymmetric

${ }^{a}$ University Chemical Laboratory, Lensfield Rd, Cambridge, UK

CB2 1EW. E-mail: ptw22@cam.ac.uk; Fax: +44 1223336017

${ }^{b}$ Instituto de Ciencia Molecular, Universidad de Valencia. Pol. La Coma s/n, 46980 Paterna, Valencia, Spain

$\uparrow$ Current address: Department of Chemistry, University of California, Berkeley, CA, USA and the Chemical Sciences Division, Lawrence Berkeley National Laboratory, CA, USA.

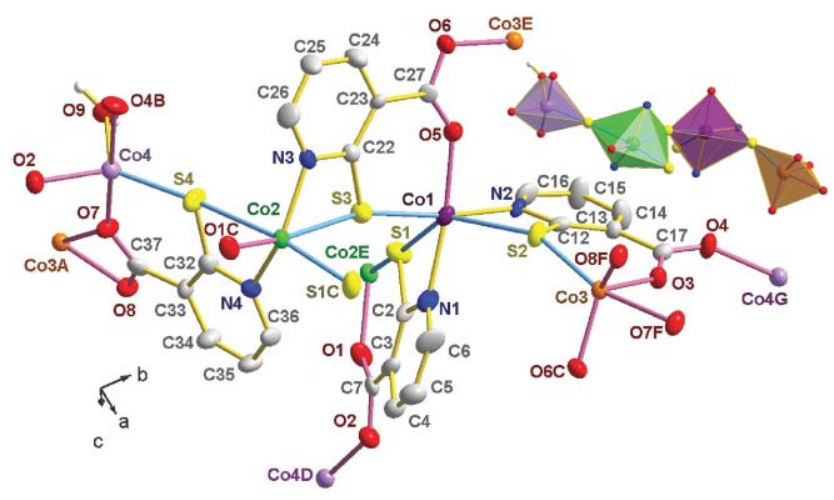

Fig. 1 The extended asymmetric unit of $\mathbf{1}$; all unique atoms shown with completed coordination environments. Co-S bonds are shown in blue, $\mathrm{Co}-\mathrm{O}$ bonds are shown in pink. Inset: polyhedral view of the same four unique $\mathrm{Co}(\mathrm{II})$ centers. Selected bond lengths $[\AA \AA]$ and angles [ $\left.{ }^{\circ}\right]$ : Co1-S1 2.652(2), Co1-S2 2.585(2), Co1-S3 2.310(2), Co2-S1C 2.288(2), Co2-S3 2.691(2), Co2-S4 2.739(2), Co3-S2 2.301(2), Co4-S4 2.266(2); S1-Co1-S2 135.62(8), S2-Co1-S3 122.83(8), S1C-Co2-S4 82.35(7), S3-Co2-S4 97.44(8), Co1-S1-Co2E 169.3(1), Co1-S2-Co3 153.4(1), Co1-S3-Co2 158.6(1), Co2-S4-Co4 165.4(1), Co3A-O7-Co4 137.7(2), O7F-Co3-O8F $58.5(2)$.

orthorhombic space group $P c a 2_{1}, Z=4$ ). The asymmetric unit contains four highly distorted $\mathrm{Co}^{\mathrm{II}}$ environments. Co1 and $\mathrm{Co} 2$ are both within distorted octahedra, $\mathrm{Co} 3$ conforms most closely to trigonal bipyramidal coordination geometry, while $\mathrm{Co} 4$ is in a square-based pyramid with a single $\mathrm{OH}_{2}$ ligand (O9) in the apical position (Fig. 1 inset). The most striking detail of the asymmetric unit of $\mathbf{1}$ is the wide range of coordination modes present between metal ions and the four unique 2-mna ligands. There are a total of six different modes: (a) all ligands form planar 4-membered N,Sdonor chelate rings to $\mathrm{Co}$ (bite angles in the range 62.4(2) $\left.64.6(2)^{\circ}\right)$; (b) each ligand also forms a near-planar 6-membered $\mathrm{S}, \mathrm{O}$-chelate ring, thus leading to pseudo-linear bridging via $\mathrm{RS}^{-}$; (c) two carboxylate groups provide syn,anti-bridges between metal ions; (d) one carboxylate moiety mediates a distorted anti,anti-type bridge; (e) there is a single chelating carboxylate; (f) a single carboxylate-O provides a 1,1'-bridge between metals. Octahedral $\mathrm{Co} 1$ and $\mathrm{Co} 2$ have 'softer' coordination environments since both are doubly N,S-chelated while each also coordinates to a third thiolate from an adjacent ligand. Single carboxylate-O donor atoms complete their coordination environments. In contrast, the environments around $\mathrm{Co} 3$ and $\mathrm{Co} 4$ comprise coordination of four O-donors and a single thiolate-S. 


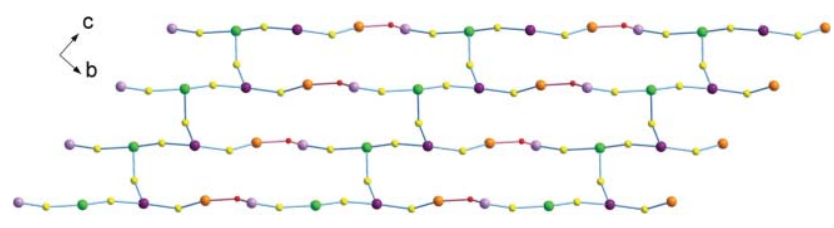

Fig. 2 The magnetic sheet of single atom O- and S-bridged sublattices comprised of 'double comb' $\mathrm{CoS}$ zigzag chains (green, purple metals) found in 1 .

The extended lattice of $\mathbf{1}$ is complex and most easily described by firstly considering its $\mathrm{CoS}$ and $\mathrm{CoO}$ sublattices (Fig. 2), since the single atom bridges (particularly thiolate) are expected to mediate the strongest magnetic exchange interactions. All four ligands in the asymmetric unit provide nearly linear $\mathrm{M}-\mathrm{S}-\mathrm{M}$ bridges (in the range 153.4(1)-169.3(1) $)$, which are expected to induce strong antiferromagnetic exchange interactions. ${ }^{8}$ Parallel $\mathrm{CoS}$ chains run along the crystallographic $c$ axis and contain all four metal centers (Co4-S-Co2-S-Co1-S-Co3). These are crosslinked by perpendicular interactions at $\mathrm{Co} 1$ and $\mathrm{Co} 2$, giving rise to a 'double comb' motif consisting of a zigzag spine of (-S1-Co1S3-Co2-) $)_{\infty}$ with (-S2-Co3) and (-S4-Co4) 'teeth' on either side. The next strongest magnetic exchange interactions in $\mathbf{1}$ will be provided by single atom-O bridges $(\mathrm{O} 7)$ which generate a brick wall' motif of $\mathrm{Co}_{10} \mathrm{~S}_{8} \mathrm{O}_{2}$ rings. These layers are joined together by $\mathrm{Co}-\mathrm{OCO}-\mathrm{Co}$ bridges to form a 3-dimensional superexchange lattice. The $\mathrm{Co}-\mathrm{O}$ lattice is also based on a double comb type topology where chains of carboxylate-bridged metals (Co1-Co3$\mathrm{Co} 4 \mathrm{Co} 3)$ are linked into zigzags at $\mathrm{Co} 3$ centers, while $(-\mathrm{OCO}-$ $\mathrm{Co} 2)$ 'teeth' terminate from $\mathrm{Co} 4$ equivalents. The 3-dimensional packing of $\mathbf{1}$ is very dense: there is little symmetry to the extended lattice and when viewed parallel to $a$ (Fig. 3a) and $b$ (Fig. 3b), its close-packed nature becomes evident; the material is essentially a 3-dimensional metal-organic 'block'. When viewed parallel to $c$, the linkage of adjacent magnetic sheets (projecting into the page) by carboxylate bridges can be seen (Fig. 3c).

The magnetic behavior of $\mathbf{1}$ has been studied using DC and AC SQUID magnetometry on polycrystalline samples. The DC data follow the Curie-Weiss law very well between 125 and $300 \mathrm{~K}$ giving $C=3.02(3) \mathrm{cm}^{3} \mathrm{~K} \mathrm{~mol}^{-1}$ (per Co(II) ion) and $\theta=-225(4)$ $\mathrm{K}$ (Fig. 4). The Curie constant, $C$, is larger than expected for an $S=3 / 2$ ion if only the spin contribution is considered. This is due to the presence of a significant orbital contribution, typical in $\mathrm{Co}(\mathrm{II})$ ions. In fact, the $C$ value is in the range observed for $\mathrm{Co}(\mathrm{II})$ ions $\left(2.7-3.4 \mathrm{~cm}^{3} \mathrm{~K} \mathrm{~mol}^{-1}\right){ }^{11}$ The Weiss temperature, $\theta$, indicates that the dominant exchange interaction is strongly antiferromagnetic. The thermal variation of the DC susceptibility $\left(\chi_{\mathrm{m}}\right)$ (Fig. 4)
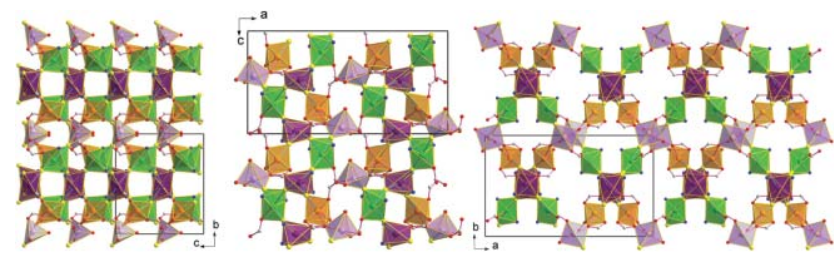

Fig. 3 (Left) Polyhedral view of $\mathbf{1}$ viewed along $a$. All aromatic carbon atoms have been omitted for clarity. (Center) Projection along $b$. (Right) Linking of 2-dimensional single atom-bridged sheets of $\mathrm{CO}^{\mathrm{II}}$ into a 3-dimensional lattice by carboxylate bridges.

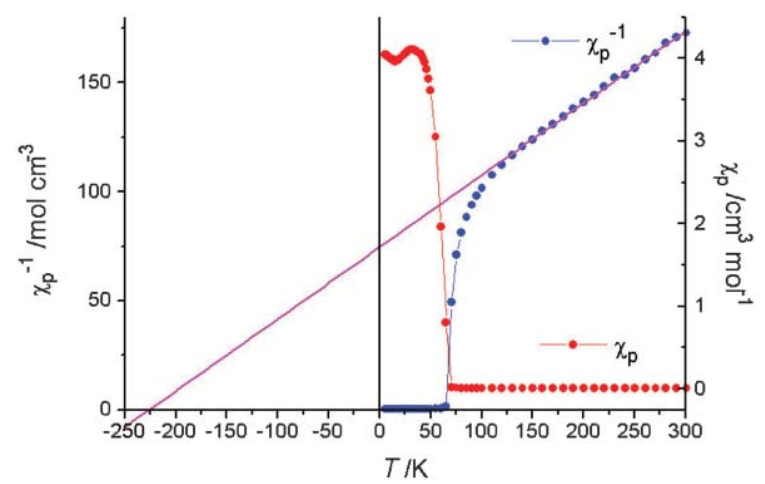

Fig. 4 Graphs of susceptibility (red) and inverse susceptibility (blue) for compound 1 along with a fit to the Curie-Weiss law.

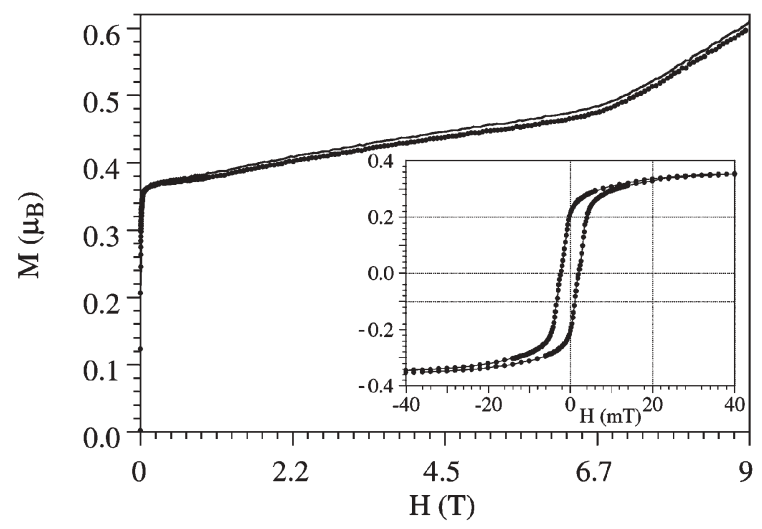

Fig. 5 Isothermal magnetization at $5 \mathrm{~K}$ of $\mathbf{1}$. Inset shows the hysteresis cycle and the rapid saturation in the low field region.

shows a sharp increase below $c a .67 \mathrm{~K}$ before reaching a maximum at $40 \mathrm{~K}$ followed by a local minimum at $15 \mathrm{~K}$ before increasing gently again as $T$ decreases. The large Weiss constant and high $T_{\mathrm{C}}$ confirm that the better energy match between metal and sulfur orbitals can lead to strengthened superexchange, as described above. Measurement of $\chi_{\mathrm{m}}$ in a range of applied fields shows that this abrupt increase is less pronounced with increasing magnetic fields due to saturation effects. This is more clearly shown in the isothermal magnetization at low temperature which shows a sharp increase to reach a saturation value of $c a .0 .35$ B.M. at magnetic fields above ca. $10 \mathrm{mT}$. For higher fields, the magnetization shows a smooth and linear increase with a change in slope at $c a .7 \mathrm{~T}$ (Fig. 5). Furthermore, the isothermal magnetization shows a hysteresis cycle with a coercive field of $c a .2 .5 \mathrm{mT}$ (inset in Fig. 5). These three facts: the abrupt increase of $\chi_{\mathrm{m}}$ below $c a .67 \mathrm{~K}$, the fast saturation of the magnetization and the presence of a hysteresis cycle, suggest the presence of a long range ordering in $\mathbf{1}$ with a $T_{\mathrm{C}}$ around $67 \mathrm{~K}$. Since the coupling is strongly antiferromagnetic and the saturation value of the magnetisation is well below the expected one for a parallel alignment of the spins of four $\mathrm{Co}(\mathrm{II})$ ions ( $c a .15$ B.M. assuming $g=2.5$, as deduced from the $C$ value), we can conclude that 1 exhibits a weak ferromagnetism due to spin canting that prevents the complete cancellation of the spins of the $\mathrm{Co}(\mathrm{II})$ ions. By comparison of the isothermal magnetisation data with the ideal value of $M_{\text {sat }}$ for ferromagnetic alignment, we estimate the canting angle to be $2.5^{\circ}$. This spin canting is favored by the single ion anisotropy of the $\mathrm{Co}(\mathrm{II})$ ions and by the four 


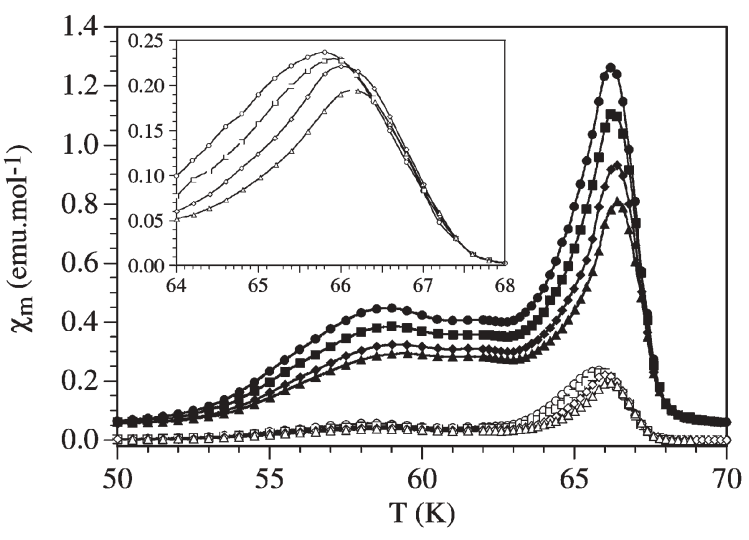

Fig. 6 Frequency dependence of the AC susceptibility of $\mathbf{1}$ at 1, 10, 110 and $332 \mathrm{~Hz}$ (circles, squares, rhombuses and triangles, respectively). $\chi^{\prime}$ filled symbols, $\chi^{\prime \prime}$ empty symbols. Inset shows the frequency dependence of the $\chi^{\prime \prime}$ peak at $c a .66 \mathrm{~K}$.

different coordination environments shown by the four Co(II) ions and is consistent with the crystallisation of $\mathbf{1}$ in a noncentrosymmetric space group.

In order to determine the critical temperature precisely, AC magnetic measurements were performed (Fig. 6). We observe a sharp increase below $c a .68 \mathrm{~K}$ and a sharp maximum in the real part of the susceptibility, $\chi_{\mathrm{m}}{ }^{\prime}$ at $66.2-66.4 \mathrm{~K}$ with a broad shoulder at $c a$. 58.9-59.4 K. This signal is accompanied by an out-of-phase signal, $\chi_{\mathrm{m}}{ }^{\prime \prime}$ that becomes non-zero below a temperature of $68.0 \mathrm{~K}$, which defines $T_{\mathrm{C}}$, with a sharp maximum at 65.8-66.2 $\mathrm{K}$ and a shoulder at $58.3-58.6 \mathrm{~K}$. This behavior confirms the presence of long range order at $T_{\mathrm{C}}=68 \mathrm{~K}$.

Interestingly, the $\chi_{\mathrm{m}}$ " maximum at $c a .66 \mathrm{~K}$ varies slightly with the frequency $(0.4 \mathrm{~K}$ in the frequency range $1-332 \mathrm{~Hz}$, inset in Fig. 6). This frequency dependence is too small to be attributed to superparamagnetic behavior of the weak ferromagnet nor to a movement of the domain walls. In fact, the activation energy calculated from an Arrhenius analysis gives a value of $4 \times 10^{4} \mathrm{~K}$, which is 400 times higher than the typical values of domain wall movements ${ }^{12}$ even allowing for the fact that in $\mathbf{1}$ we should expect a high activation energy as a result of single ion effects and the strong coupling encountered. A plausible explanation may be a spin glass-like behavior since 1 presents simultaneous ferro- (from the spin canting) and antiferromagnetic (from the many $-\mathrm{S}-,-\mathrm{O}$ and - $\mathrm{OCO}$ - bridges) exchange couplings and may present some degree of frustration in the very complex magnetic lattice. Finally, the needed randomness in the magnetic lattice may arise from crystal defects and/or from the presence of up to four different coordination environments in the Co(II) ions. ${ }^{13}$ The same features were observed when measurements were performed on a Nujolrestrained sample. This confirms that this behavior is actually intrinsic for this compound, and not sample dependent.

In conclusion, we have shown that hydrothermal synthesis is an effective way of preventing disulfide formation in reactions intended to produce metal thiolates. We confirm that hydrothermal synthesis is also a good method for preparing intricate coordination networks. Most importantly, this work shows that the incorporation of thiolate bridges is indeed a route to magnetic networks with higher ordering temperatures.

\section{Notes and references}

\$ Synthesis of 1. To a stirred solution of 2-mercaptonicotinic acid $(1.0 \mathrm{mmol})$ and $\mathrm{NaOH}\left(1.0 \mathrm{M}, 1.9 \mathrm{~cm}^{3}\right)$ in $\mathrm{H}_{2} \mathrm{O}\left(3.1 \mathrm{~cm}^{3}\right)$ was added a solution of $\mathrm{CoCl}_{2}(1.0 \mathrm{mmol})$ in $\mathrm{H}_{2} \mathrm{O}\left(5 \mathrm{~cm}^{3}\right)$ to give an opaque purple slurry (ratio $=1: 1: 1.9$ ). The mixture was heated for $15 \mathrm{~h}$ at $210{ }^{\circ} \mathrm{C}$ and cooled slowly $\left(0.10^{\circ} \mathrm{C} \mathrm{min}-1\right)$ to yield fine deep red crystals in high purity (yield $153 \mathrm{mg}, 71 \%$ ). Anal. found: $\mathrm{C}, 32.7 ; \mathrm{H}, 1.6 ; \mathrm{N}, 6.2$. $\mathrm{C}_{24} \mathrm{H}_{14} \mathrm{Co}_{4} \mathrm{~N}_{4} \mathrm{O}_{9} \mathrm{~S}_{4}$ requires: C, 33.3; H, 1.6; N, 6.5\%. $\lambda_{\max }$ (powder $/ \mathrm{nm}$ ): 565(0.69), 527(0.69), 425(0.89). $v_{\max }\left(\mathrm{KBr} / \mathrm{cm}^{-1}\right): 3422 \mathrm{~m}, 3067 \mathrm{w}, 1583 \mathrm{~s}$, $1566 \mathrm{~m}, 1534 \mathrm{~m}, 1500 \mathrm{w}, 1448 \mathrm{~m}, 1396 \mathrm{~s}, 1370 \mathrm{~m}, 1243 \mathrm{~m}, 1155 \mathrm{~m}, 1134 \mathrm{~m}$, 1093 m, 1062 w, 1007 w, 962 w, 879 m, 763 m, 727 w, 668 m.

§ Crystal data. $\mathrm{C}_{24} \mathrm{H}_{14} \mathrm{Co}_{4} \mathrm{~N}_{4} \mathrm{O}_{9} \mathrm{~S}_{4}, \quad M=866.35$, orthorhombic, $a=$ 20.8760(6), $b=12.3647(2), c=10.9125(2) \AA, V=2816.79(11) \AA^{3}, T=$ $180(2) \mathrm{K}$, space group $P c a 2_{1}, Z=4, \mu(\mathrm{Mo}-\mathrm{K} \alpha)=2.673 \mathrm{~mm}^{-1}, 15465$ reflections measured, 4610 unique $\left(R_{\text {int }}=0.0688\right)$. Final values $R 1=0.0598$ and $\mathrm{w} R 2=0.0932$ (all data). CCDC 287016. For crystallographic data in CIF or other electronic format see DOI: $10.1039 / \mathrm{b} 600347 \mathrm{~h}$

1 For recent reviews, see: (a) C. Janiak, Dalton Trans., 2003, 14, 2781; (b) E. Coronado, A. Forment-Aliaga, J. R. Galan-Mascaros, C. GimenezSaiz, C. J. Gomez-Garcia, E. Martinez-Ferrero, A. Nuez and F. M. Romero, Solid State Sci., 2003, 5, 917; (c) D. Maspoch, D. Ruiz-Molina and J. Veciana, J. Mater. Chem., 2004, 14, 2713; (d) L. Ouahab, Coord. Chem. Rev., 1998, 178-180, 1501; (e) C. Janiak, Angew. Chem., Int. Ed. Engl., 1997, 36, 1434.

2 See for example: H. Li, M. Eddaoudi, M. O'Keeffe and O. M. Yaghi, Nature, 1999, 402, 276; P. M. Forster, J. Eckert, J.-S. Chang, S.-E. Park, G. Férey and A. K. Cheetham, J. Am. Chem. Soc., 2003, 125, 1309; A. Zecchina, S. Bordiga, J. G. Vitillo, G. Ricchiardi, C. Lamberti, G. Spoto, M. Bjørgen and K. P. Lillerud, J. Am. Chem. Soc., 2005, 127, 6361; S. S. Kaye and J. R. Long, J. Am. Chem. Soc., 2005, 127, 6506; S. Noro, S. Kitagawa, M. Kondo and K. Seki, Angew. Chem., Int. Ed., 2000, 39, 2082

3 Q. Ye, Y. H. Li, Y. M. Song, X. F. Huang, R. G. Xiong and Z. Xue, Inorg. Chem., 2005, 44, 3618

4 See for example: E. Coronado, M. Clemente-Leon, J. R. GalanMascaros, C. Gimenez-Saiz, C. J. Gomez-Garcia and E. MartinezFerrero, J. Chem. Soc., Dalton Trans., 2000, 21, 3955; G. Zu, Z. M. Wang, Z. He, Z. Lu, C. S. Liao and C. H. Yan, Inorg. Chem., 2002, 41, 6802; R. Sessoli, D. Gatteschi, A. Caneschi and M. A. Novak, Nature, 1993, 365, 141.

5 S. Hermes, M. K. Schröter, R. Schmid, L. Khodeir, M. Muhler, A. Tissler, R. W. Fischer and R. A. Fischer, Angew. Chem., Int. Ed., 2005, 44, 6237.

6 H. Ohno, Science, 2001, 291, 840; J. J. Attema, G. A. de Wijs, G. R. Blake and R. A. de Groot, J. Am. Chem. Soc., 2005, 127, 16325; S. A. Wolf, D. D. Awschalom, R. A. Buhrman, J. M. Daughton, S. von Molnar, M. L. Roukes, A. Y. Chtchelkanova and D. M. Treger, Science, 2001, 294, 1488.

7 L. A. Gerrard and P. T. Wood, Chem. Commun., 2000, 2107; S. M. Humphrey and P. T. Wood, J. Am. Chem. Soc., 2004, 126, 13236; S. O. H. Gutschke, A. M. Z. Slawin and P. T. Wood, J. Chem. Soc., Chem. Commun., 1995, 2197.

8 S. Ferlay, T. Mallah, R. Ouahes, P. Veillet and M. Verdaguer, Nature, 1995, 378, 701

9 O. Kahn, Molecular Magnetism, Wiley-VCH, Weinheim, 1993.

10 S. M. Humphrey, R. A. Mole, M. McPartlin, E. J. L. McInnes and P. T. Wood, Inorg. Chem., 2005, 44, 5981; S. M. Humphrey, R. A. Mole, J. M. Rawson and P. T. Wood, Dalton Trans., 2004, 1670; D. Cave, J.-M. Gascon, A. D. Bond, S. J. Teat and P. T. Wood, Chem. Commun. 2002, 1050

11 R. March, W. Clegg, R. A. Coxall, L. Cucurull-Sánchez, L. Lezama, T. Rojo and P. González-Duarte, Inorg. Chim. Acta, 2003, 353, 129.

12 F. Bellouard, M. Clemente-Leon, E. Coronado, J. R. Galan-Mascaros, C. J. Gomez-Garcia, F. Romero and K. R. Dunbar, Eur. J. Inorg. Chem., 2002, 1603; E. Coronado, C. J. Gómez-García, A. Nuez, F. M. Romero, E. Rusanov and H. Stoeckli-Evans, Inorg. Chem., 2002, 41, 4615.

13 J. A. Mydosh, Spin glasses: an experimental introduction, Taylor and Francis, London, 1993. 